\title{
Postoperative Pain Score of Bupivacaine versus Placebo in Patients Undergoing Percutaneous Nephrolithotomy
}

\author{
Shariq Anis Khan1, Salman el Khalid1, Fouzia Naeem Effendi2, Mohammad Hammad Mithani1, \\ Adnan Siddique Awan ${ }^{1}$ and Tooba Mugal1
}

\begin{abstract}
Objective: To compare postoperative mean pain score of bupivacaine versus placebo in patients undergoing percutaneous nephrolithotomy.

Study Design: An experimental study.

Place and Duration of Study: Department of Urology, The Kidney Centre, Postgraduate Training Institute (PGTI), Karachi, from November 2014 to December 2015.

Methodology: A total of 94 patients who underwent standard percutaneous nephrolithotomy, clinically diagnosed renal stone by CT scan, KUB, X-ray or ultrasound were included in the study. Patients were randomly divided into two groups. Forty-seven patients in group A were treated with $20 \mathrm{ml} / 50 \mathrm{mg}$ of $0.25 \%$ bupivacaine; and 47 patients in group B were treated with normal saline. Postoperatively, visual analog score was used to assess the pain at 6, 12 and 24 hours. Data was analysed using SPSS version 20.0 and student t-test was applied for comparison between the groups.

Results: The average age of the patients was $37.23 \pm 11.31$ years. Mean pain score in 24 hours was low in group A as compared to group B $(5.22 \pm 0.76$ vs. $7.85 \pm 0.78$; $p<0.001)$.

Conclusion: Bupivacaine infiltration into the nephrostomy tract is a highly effective and safe in postoperative pain management for patients undergoing standard PCNL.
\end{abstract}

Key Words: Percutaneous nephrolithotomy, Postoperative pain, Bupivacaine.

\section{INTRODUCTION}

Percutaneous nephrolithotomy (PCNL) is a minimally invasive procedure and considered to be a standard treatment option for large renal calculi because of its high stone clearance and low complications. ${ }^{1-3}$ In standard PCNL, nephrostomy tube placement is aimed at tamponade effect, second-look surgery and for drainage.4-6 However, one of the major issues seen in patient undergoing standard PCNL is postoperative pain and discomfort at the nephrostomy site, ${ }^{7}$ which results in increased hospital stay, increased requirement of analgesia; and eventually affects overall recovery of the patient. The analgesics have their own adverse effects and limitations. ${ }^{8}$

It has been reported that there is no standard approach for the management of postoperative pain after PCNL.9 However, various treatment modalities have been suggested like narcotics and non-narcotics analgesics, patient control analgesia pumps, single dose subarachnoid anesthesia, and local infiltration of anesthetic agents.10-14 Although the use of small size nephrostomy tube has showed decrease in analgesia

Department of Urologyl / Research ${ }^{2}$, The Kidney Centre,

Postgraduate Training Institute, Karachi, Pakistan

Correspondence: Dr. Shariq Anis Khan, Department of Urology,

Kidney Centre, Postgraduate Training Institute, Karachi,

Pakistan

E-mail: shaqsak@hotmail.com

Received: December 13, 2017; Accepted: July 05, 2018 requirement as well, it does not significantly give relief to the patient and hinders in postoperative smooth recovery. 15

Some studies have shown a reduction in the postoperative analgesia requirement when bupivacaine was infiltrated at the nephrostomy site, which includes skin, subcutaneous tissue, muscle and renal capsule but they have limitations as patient with stone $>3.0 \mathrm{~cm}$ size, BMI $>30$ and $A S A>2$ were excluded. ${ }^{13-18}$

To the best of authors' knowledge, there is no published local literature which can determine the efficacy of bupivacaine in this context. The aim of this study was to compare the postoperative mean pain score of bupivacaine vs. placebo in patients undergoing percutaneous nephrolithotomy.

\section{METHODOLOGY}

This experimental study was carried out in the Department of Urology, The Kidney Centre, PGTI, Karachi. Data collection from November 2014 to December 2015. Sample size was calculated by using Open epi sample size calculator by taking a mean \pm standard deviation of pain at 24 hours in bupivacaine vs. placebo that is 4.1 \pm 1.1 vs. $5.1 \pm 1.7$. 9 Power of the test was $90 \%$, level of significance $5 \%$, then the estimated sample size was at least $n=47$ in each group. The total sample size was 94 . All participants fulfilling the inclusion criteria, undergoing standard PCNL, diagnosed renal stone by CT scan, KUB, X-ray or ultrasound of either gender within the age 
group of 20-60 years and consenting to participate, were selected through simple random sampling technique.

After taking Ethical Review Committee approval, patients meeting the inclusion criteria included; and informed consent was taken. The patient was randomised into test (Group A) and control (Group B) by lottery method. Group A received $20 \mathrm{ml} / 50 \mathrm{mg}$ of $0.25 \%$ bupivacaine and Group B received $20 \mathrm{ml}$ of normal saline. All the patients received standard general anesthesia. With a 1-2 cm incision at the loin, the percutaneous nephrostomy needle was passed into the kidney pelvis and confirmed by fluoroscopy, a guide wire was passed and working sheath was introduced after serial dilatation with Allen's metallic dilator.

A nephroscope was then passed through the amplatz working sheath and stone was fragmented and removed. Finally, a nephrostomy tube was placed at the puncture site. After fixation of the nephrostomy tube, 22-gauge spinal needle was used to infiltrated bupivacaine or normal saline from the renal capsule to the skin under ultrasound and fluoroscopic guidance at 3, 6, 9, 12 o'clock position around nephrostomy tube. Postoperatively, visual analog scale (VAS) (0 meaning no pain and 10 meaning unbearable pain) was used to assess the pain by an independent observer, blinded to the randomisation at 6,12 and 24 hours. After 24 hours, mean of VAS, as mentioned in the operational definition, was calculated and noted on performa.

Data was analysed using SPSS version 20.0. Mean \pm standard deviation and confidence interval was calculated for age and pain score. Frequency and

Table I: Comparison of mean pain score between groups.

\begin{tabular}{l|c|c|c}
\hline VAS & $\begin{array}{c}\text { Group A } \\
\mathrm{n}=47\end{array}$ & $\begin{array}{c}\text { Group B } \\
\mathrm{n}=47\end{array}$ & p-value \\
\hline At 6 hours & $4.23 \pm 1.02$ & $8.47 \pm 1.12$ & $<0.001$ \\
\hline At 12 hours & $5.53 \pm 1.26$ & $7.85 \pm 1.17$ & $<0.001$ \\
\hline At 24 hours & $5.91 \pm 1.10$ & $7.23 \pm 1.15$ & $<0.001$ \\
\hline Mean VAS in 24 hours & $5.22 \pm 0.76$ & $7.85 \pm 0.78$ & $<0.001$ \\
\hline
\end{tabular}

percentage was calculated for gender. Student $\mathrm{t}$-test was applied to compare mean VAS at 24 hours postoperatively in both groups. The $p \leq 0.05$ was considered significant. Confounders were controlled by stratification for age and gender. To determine the effect of outcome variables, post-stratification applying student t-test, $p \leq 0.05$ was considered significant.

\section{RESULTS}

A total of 94 patients undergoing standard PCNL were included in this study. Forty-seven patients in group $A$ were treated with $20 \mathrm{ml} / 50 \mathrm{mg}$ of $0.25 \%$ bupivacaine and 47 patients in group $B$ were treated with normal saline. The average age of the patients was 37.23 \pm 11 .31 years. Age distribution with respect to groups is presented in Figure 1. Average age $(p=0.48)$ and stone size $(p=0.28)$ of the patients were insignificant between groups as shown in Table I. There were 69 (73.4\%) male and $25(26.6 \%)$ female patients.



Figure 1: Age distribution of the patients.

Table II: Comparison of mean pain score between groups for above 40 years of age and less and equal to 40 years of age cases.

\begin{tabular}{l|c|c|c|c|c|c}
\hline VAS & $\begin{array}{c}\text { Group A } \\
\text { (Above 40) } \\
\mathrm{n}=20\end{array}$ & $\begin{array}{c}\text { Group B } \\
\text { (Above 40) } \\
\mathrm{n}=18\end{array}$ & $\mathrm{p}$-value & $\begin{array}{c}\text { Group A } \\
(<\mathrm{or}=40) \\
\mathrm{n}=27\end{array}$ & $\begin{array}{c}\text { Group B } \\
(<\mathrm{or}=40) \\
\mathrm{n}=29\end{array}$ & $\begin{array}{c}\mathrm{p} \text {-value } \\
\text { At 6 hours }\end{array}$ \\
\hline At 12 hours & $4.40 \pm 0.82$ & $8.89 \pm 1.02$ & $<0.001$ & $4.11 \pm 1.15$ & $8.21 \pm 1.11$ & $<0.001$ \\
\hline At 24 hours & $5.50 \pm 1.10$ & $8.22 \pm 0.94$ & $<0.001$ & $5.56 \pm 1.39$ & $7.62 \pm 1.26$ & $<0.001$ \\
\hline Mean VAS in 24 hours & $5.70 \pm 0.73$ & $7.44 \pm 1.34$ & $<0.001$ & $6.07 \pm 1.29$ & $7.10 \pm 1.01$ & $<0.002$ \\
\hline
\end{tabular}

Table III: Comparison of mean pain score between groups for male and female cases.

\begin{tabular}{|c|c|c|c|c|c|c|}
\hline VAS & $\begin{array}{c}\text { Group A } \\
\text { (males) } \\
n=15\end{array}$ & $\begin{array}{c}\text { Group B } \\
\text { (males) } \\
n=10\end{array}$ & p-value & $\begin{array}{c}\text { Group A } \\
\text { (females) } \\
n=32\end{array}$ & $\begin{array}{c}\text { Group B } \\
\text { (females) } \\
n=37\end{array}$ & p-value \\
\hline At 6 hours & $3.80 \pm 0.41$ & $9 \pm 1.05$ & $<0.001$ & $4.44 \pm 1.16$ & $8.32 \pm 1.11$ & $<0.001$ \\
\hline At 12 hours & $6.40 \pm 1.12$ & $7.70 \pm 0.94$ & 0.006 & $5.13 \pm 1.12$ & $7.89 \pm 1.24$ & $<0.001$ \\
\hline At 24 hours & $6.53 \pm 0.91$ & $7.60 \pm 1.26$ & 0.022 & $5.63 \pm 1.07$ & $7.14 \pm 1.11$ & $<0.001$ \\
\hline Mean VAS in 24 hours & $5.57 \pm 0.53$ & $8.1 \pm 0.49$ & $<0.001$ & $5.06 \pm 0.80$ & $7.78 \pm 0.83$ & $<0.001$ \\
\hline
\end{tabular}


Mean pain score at 6,12 and 24 hours, was significantly low in group A as compared to group B. Similarly, mean pain score in 24 hours was also low in group $A$ as compared to group $B(5.22 \pm 0.76$ vs. $7.85 \pm 0.78$; $\mathrm{p}=0.001$ ) as presented in Table II. Average total analgesia in 24 hours was significantly low in group $A$ as compared to group B (189.89 \pm 65.25 vs. $284.04 \pm 70.79$; $p=0.001$ ) while mean procedure end time was not significant between groups $(p=0.86)$ as shown in Table III.

Stratification was also performed to observe the effect of age and gender, it was observed that average pain score was significantly low in group $A(5.24 \pm 0.91)$ as compared to group B $(7.64 \pm 0.85)$ for the below and equal to 40 years of age patients; and above 40 years of age patients $(p=0.001)$. Similar significant difference was also observed for male $(p=0.001)$ and female $(p=0.001)$ patients.

\section{DISCUSSION}

The treatment of renal calculi has evolved during the last three decades from open surgical procedures to noninvasive modalities like extracorporeal shockwave lithotripsy and less invasive procedures like PCNL. $P C N L$ is a safe and effective endourological procedure for the management of patients with renal calculi as it is less invasive than the open surgery. This technique of PCNL has stood the test of time because of excellent stone-free rates coupled with very low complications. ${ }^{18}$ Placement of nephrostomy tube after completion of PCNL is a standard procedure to provide haemostasis, adequate drainage, and access for additional endoscopic procedures for 48 hours. Recently, tubeless PCNL has come into vogue with significant reduction in the postoperative pain in selected group of patients. ${ }^{19}$ However, nephrostomy tube cannot be dispensed in cases like complex stones, perforation, and excess bleeding.

Postoperative inadequate analgesia can result in delayed mobilisation, impaired ventilation, and prolonged hospitalisation. Analgesics such as non-steroidal antiinflammatory drugs and opioids have side effects limiting their use in patients with potential renal problems. Effective pain management is essential and has been recognised as a prime concern for anaesthesiologists. 20 Local infiltration of local analgesia has been introduced as a promising step forward in reducing postoperative pain and side effects from analgesics.

Local infiltration at the surgical site has become relatively common for a number of surgical procedures and can produce effective analgesia and has the advantage of relative simplicity compared with other regional anaesthesia techniques. In this study, after PNCL, 22 gauge spinal needle was used to infiltrate bupivacaine or normal saline from the renal capsule to the skin under ultrasound and fluoroscopic guidance at $3,6,9,12$ o'clock position around nephrostomy tube.
Similar method was used by Keric et al. in their study, ${ }^{8}$ at the end of the PCNL procedure; the group 1 patients received a $20-\mathrm{mL}$ infiltration of $0.25 \%$ bupivacaine. Under fluoroscopic guidance, the local analgesic was infiltrated with a 22-gauge spinal needle (10-cm length) along the nephrostomy tract at the 3,6, 9, and 12 o'clock positions $(5 \mathrm{ml}$ in each tract), including the muscles, subcutaneous tissue, and skin.

Out of 94 patients in this study, the average age of the patients was $37.23 \pm 11.31$ years, $73.4 \%$ males and $26.6 \%$ were females, similar predominance was reported by other studies. ${ }^{15,21}$ Keric et al. reported that the mean age as $43.2 \pm 12.7$ years (range, 18-74 years), with $41.4 \%$ females and $58.6 \%$ males. $^{8}$

In this study, out of 94 patients, 47 patients in group A were treated with $20 \mathrm{ml} / 50 \mathrm{mg}$ of $0.25 \%$ bupivacaine; and 47 patients in group $B$ were treated with normal saline. Mean pain score at 6,12 and 24 hours, was significantly low in group A as compared to group B. Similarly, mean pain score in 24 hours was also low in group $A$ as compared to group B. Average total analgesia in 24 hours was significantly lower in group A as compared to group B. Similarly, Jonnavithula and colleagues in a randomised controlled study, 13 infiltrated $20 \mathrm{~mL}$ of $0.25 \%$ bupivacaine along the nephrostomy tube at 6 o'clock and 12 o'clock positions $(10 \mathrm{~mL}$ in each tract), reportedly found their technique to be associated with significant reduction in pain scores and analgesic requirement without any complications. Andreoni and colleagues noted in a randomised trial that a single preoperative dose of subarachnoid spinal analgesia with morphine along with infiltration of the nephrostomy tract with bupivacaine was associated with a statistically significant decrease in the requirement of postoperative parenteral pain medication. 22 Haleblian et al. conducted a study on subcutaneous infiltration of $1.5 \mathrm{mg} / \mathrm{kg}$ of $0.25 \%$ bupivacaine versus saline after PCNL in 25 patients. 13 Their results showed reduced rescue analgesic requirement in bupivacaine group, but no significant difference in pain score was found in both groups. Contrary to the above findings, Gokten and associates infiltrated $20 \mathrm{ml}$ of $0.25 \%$ levobupivacaine through the entire nephrostomy tract, which included skin, subcutaneous tissue, and muscles, just before puncture of PCNL.23 In spite of using preemptive analgesia, they failed to show any major advantage of local anesthetic infiltration over a saline infiltration. Hantrakun evaluated the effectiveness of peritubal bupivacaine infiltration for postoperative pain control after PCNL found that peritubal infiltration of $0.25 \%$ bupivacaine $20 \mathrm{ml}$. is not efficient for postoperative pain control after PCNL. 24

\section{CONCLUSION}

The results of the present study demonstrate that bupivacaine infiltration into the nephrostomy tract is 
highly effective and is a safe technique in postoperative pain management for patients undergoing standard PCNL. This effect leads to lower early postoperative pain (less VAS score), less number of opioid usage and longer time of first analgesic requirement.

Disclosure: This study was part of FCPS dissertation.

\section{REFERENCES}

1. Karaduman I, Karasu D, Yilmaz C, Oner S, Erdem Solak H, Korfali G. The effect of peritubal infiltration with bupivacaine and morphine on postoperative analgesia in patients undergoing percutaneous nephrolithotomy. Pain Res Manag 2017; 2017:2454267.

2. Wang J, Zhang C, Tan D, Tan G, Yang B, Chen W, et al. The effect of local anesthetic infiltration around nephrostomy tract on postoperative pain control after percutaneous nephrolithotomy: a systematic review and meta-analysis. Urol Int 2016; 97:125-33.

3. de la Rosette J, Assimos D, Desai M, Gutierrez J, Lingeman J, Scarpa $\mathrm{R}$, et al. The clinical research office of the endourological society percutaneous nephrolithotomy global study: indications, complications, and outcomes in 5803 patients. $J$ Endourol 2011; 25:11-7.

4. Sofer M, Lidawi G, Keren-Paz G, Yehiely R, Beri A, Matzikin H. Tubeless percutaneous nephrolithotomy: first 200 cases in Israel. Isr Med Assoc J 2010; 12:164-7.

5. Istanbulluoglu M, Cicek T, Ozturk B, Gonen M, Ozkardes H. Percutaneous nephrolithotomy: nephrostomy or tubeless or totally tubeless? Urology 2010; 75:1043-6.

6. Bellman GC, Davidoff R, Candela J, Gerspach J, Kurtz S, Stout L. Tubeless percutaneous renal surgery. J Urol 1997; 157:1578-82.

7. Pietrow PK, Auge BK, Lallas CD, Santa-Cruz RW, Newman GE, Albala DM, et al. Pain after percutaneous nephrolithotomy: impact of nephrostomy tube size. J Endourol 2003; 17: 4114.

8. Gupta NP, Mishra S, Suryawanshi M, Seth A, Kumar R. Comparison of standard with tubeless percutaneous nephrolithotomy. J Endourol 2008; 22:1441-6.

9. Kirac M, Tepeler A, Bozkurt OF, Elbir F, Ozluk C, Armagan A, et al. The efficacy of bupivacaine infiltration on the nephrostomy tract in tubeless and standard percutaneous nephrolithotomy: a prospective, randomized, multicenter study. Urology 2013; 82:526-31.

10. Haleblian GE, Sur RL, Albala DM, Priminger GM. Subcutaneous bupivacaine infiltration and postoperative pain perception after percutaneousnephrolithotomy. J Urol 2007; 178:925-8.

11. Ugras MY, Toprak HI, Gunen H, Yucel A, Gunes A. Instillation of skin, nephrostomy tract, and renal puncture site with ropivacaine decreases pain and improves ventilatory function after percutaneous nephrolithotomy. J Endourol 2007; 21:499-503.

12. Andreoni C, Olweny EO, Portis AJ, Sundaram CP, Monk T, Clayman RV. Effect of single-dose subarachnoid spinal anesthesia on pain and recovery after unilateral percutaneous nephrolithotomy. J Endourol 2002; 16:721-5.

13. Jonnavithula N, Pisapati MV, Durga P, Krishnamurthy V, Chilumu R, Reddy B. Efficacy of peritubal local anesthetic infiltration in alleviating postoperative pain in percutaneous nephrolithotomy. J Endourol 2009; 23:857-60.

14. Gokten OE, Kilicarslan H, Dogan HS, Turker G, Kordan Y. Efficacy of levobupivacaine infiltration to nephrosthomy tract in combination with intravenous paracetamol on postoperative analgesia in percutaneous nephrolithotomy patients. $J$ Endourol 2011; 25:35.

15. Parikh GP, Shah VR, Modi MP, Chauhan NC. The analgesic efficacy of peritubalin filtration of $0.25 \%$ bupivacaine in percutaneous nephrolithotomy - a prospective randomized study. J Anaesthesiol Clin Pharmacol 2011; 27:481-4.

16. Alam Z, Biyabani R, Ather MH. Impact of nephrostomy tube size on post-operative pain and perinephric collection after percutaneous nephrolithotomy - a randomized controlled study. Eur Urol Suppl 2009; 8:573.

17. Parikh GP, Shah VR, Vora KS, Modi MP, Mehra T, Sonde S. Analgesic efficacy of peritubal infiltration of ropivacaine versus ropivacaine and morphine in percutaneous nephrolithotomy under ultrasonic guidance. Saudi J Anaesth 2013; 7:118-21

18. Ni S, Qiyin C, Tao W, Liu L, Jiang H, Hu H. Tubeless percutaneous nephrolithotomy is associated with less pain and shorter hospitalization compared with standard or small bore drainage: A meta-analysis of randomized, controlled trials. Urology 2011; 77:1293-8.

19. Karami H, Gholamrezaie HR. Totally tubeless percutaneous nephrolithotomy in selected patients. J Endourol 2004; 18:475-6.

20. Malik P, Manchandana CC, Malhotra N. Comparative evaluation of epidural fentanyl and butorphanol for postoperative analgesia. J Anaesth Clin Pharmacol 2006; 22:377-82.

21. Hemendra N, Rashmi H, Shah Hiren S. A randomized control trial evaluating efficacy of nephrostomy tract infiltration with bupivacaine after tubeless percutaneous nephrolithotomy. J Endourol 2012; 26:12.

22. Streem SB, Yost A, Dolmatch B. Combination "sandwich" therapy for extensive renal calculi in 100 consecutive patients: immediate, long-term and stratified results from a 10-year experience. J Urol 1997; 158:342.

23. Matlaga BR, Assimos DG. Changing indications of open stone surgery. Urology 2002; 59:490.

24. Hantrakun O. Efficacy of peritubal bupivacaine infiltration for postoperative pain control after percutaneous nephrolithotomy. 2010; 25:25. 